\title{
Freezing Out the Mexican Cops: Bullying as Discrimination at the Police Workplace in Mexico City
}

\author{
Gustavo Fondevila*
}

\begin{abstract}
Centro de Investigación y Docencia Económicas - CIDE (Center for Research and Teaching in Economics), Carretera Mexico - Toluca 3655, Col. Lomas de Santa Fe (01210), Mexico City, Mexico
\end{abstract}

\begin{abstract}
In recent years, bullying problems in public security or defense institutions have been studied. Such problems are associated with high stress situations, a large workload and pressure in hierarchical organisms that base their success on a rigid system of asymmetric power and authoritarian leadership style. The aim of the current study is to investigate (in-depth interviews and ethnographic work) the patterns of the victims' subjective cultural perception of a particular type of bullying called freezing out in the Mexico City police forces and the victim's strategies to avoid it, taking into account their ranks within the structure of the police organization. The key research question is the following: How is the bullying experience called "freezing ouf" culturally perceived by self-identified targets and how do the victims cope with it? In freezing, the superior officer simply leaves his subordinate without specific instructions (it is not isolation). This could manifest itself as a type of informal punishment or as a desire to exclude the individual from the institution's work production, temporarily or permanently. The present paper is a case study that analyzes the cultural perception of freezing as social discrimination in the Mexican police force.
\end{abstract}

Keywords: Bullying, police workplace, freezing, cultural perception, discrimination, Mexico City.

\section{INTRODUCTION}

In recent years, bullying problems in public security or defense institutions have been studied (Archer, 1999; Di Martino, 2003; Dick, 2008). Police agencies seem to be the ideal structures for the appearance and promotion of this phenomenon. Such problems are associated with high stress situations (Tuckey, 2009), a large workload and pressure (Bowling \& Beehr, 2006; Hauge et al., 2007, Baillien et al., 2008; Baillien \& De Witte, 2009) in hierarchical organisms that base their success on a rigid system of asymmetric power (Archer, 1999) and authoritarian leadership style (Seigne, 1998). Importantly, these characteristics decrease the likelihood that the perpetrator suffers the consequences of his actions (Salin, 2003).

In this context, the aim of the current study is to investigate the patterns of the victims' subjective cultural perception of a particular type of bullying called freezing out in the Mexico City police forces and the strategies that the victims adopt to avoid it (Hoel \& Cooper, 2000: 17), taking into account their ranks within the structure of the police organization. The key research question is the following: How is the bullying experience called "freezing ouf" culturally perceived by self-identified targets and how do the victims cope with it? (Lynch, 2002: 7). In freezing, the superior officer simply leaves his subordinate without specific

*Address correspondence to this author at the Centro de Investigación y Docencia Económicas - CIDE (Center for Research and Teaching in Economics), Carretera Mexico - Toluca 3655, Col. Lomas de Santa Fe (01210), Mexico City, Mexico; Tel: +525557279800; Fax: +525557279856; E-mail: gustavo.fondevila@cide.edu instructions (it is not isolation, although isolation could be an effect). Slowly or abruptly, the superior officer reduces the subordinate's activities until he or she has practically nothing to do on the job. This could manifest itself as a type of informal punishment or as a desire to exclude the individual from the institution's work production, temporarily or permanently.

There are several works oriented towards the victims' perception of bullying, strategies to avoid and cope with it (Hogh \& Dofradottir, 2001; Jóhannsdóttir \& Ólafsson, 2004; Djurkovic et al., 2005), and the cultural differences between countries that can influence the victims' perception and responses to it (Paoli \& Merllié, 2001).

The present paper is a case study that analyzes the cultural perception of freezing as social discrimination in the Mexican police force.

\section{LITERATURE}

Workplace bullying is a negative labor behavior between superior and inferior levels or between peer/co-workers (Cleveland \& Kerst, 1993, Einarsen, 2000 ) in an organization. The victim is submitted to direct or indirect abuse and systematic attacks over a long and continuous period of time from one or more people (verbal abuse, unjustified criticism, malicious rumors, isolation, victimization, "under-work", etc.). It alludes to psychological violence (Di Martino et al., 2003), although some authors include physical abuse (Brodsky, 1976). Often, the objective is to eliminate the victims by cutting off communication channels, 
reducing their interaction with colleagues and reducing their work-related responsibilities within the organization so that they will eventually quit (Einarsen et al., 1994; Rayner et al., 2002; Niedl, 1995; Salin, 2003; Vartia, 1996; Zapf et al., 1996a).

Bullying cannot be strictly defined as worker harassment-mobbing (Lynch, 2002: 3-4). Bullying refers to an aggressive behavior from a person in a position of greater power (Björkqvist et al., 1994; Niedl, 1995; Einarsen et al., 2003; Tuckey, 2009; although some authors discuss the model of "power deficient target", Lutgen-Sandvik, 2006), whereas mobbing refers to horizontal (or peer-to-peer) abuse (Hartig et al., 2006: 1-2). However, despite differences between types of aggression, general criteria can be established to identify bullying with regards to other types of aggression. In this context, bullying includes the following: 1) a pattern of behavior: it is not an isolated behavior (Leymann, 1996; Chappell \& Di Martino, 1998), 2) a negative action: this refers to aggressive and destructive actions, verbal and non-verbal (Leymann, 1996; Einarsen et al., 2003), 3) unequal power relationships: the players are commonly in asymmetrical relationships (Hoel \& Cooper, 2000; Vartia, 1996), 4) a victim: this type of abuse always produces victims (McCarthy et al., 1995; Ayoko et al., 2003).

Not all repeated patterns of behavior, negative actions, abuse in asymmetrical relationships and offenses with victims are deemed as bullying; however, these conditions are necessary for bullying. Aggressions, tensions among colleagues, hierarchical conflicts and others can be habitual in work relations and not necessarily considered abuse or work harassment. Based on these common points, the literature on bullying presents the following aspects of bullying (Einarsen \& Skogstad, 1996; Knorz \& Zapf, 1996, Nielsen et al., 2004): a) the post-traumatic effects: psychological or physical; b) the aware/unaware character of the abuser; c) the open and hidden character of the action. The consequences for the institution are typically as follows (Randall, 1997; Namie \& Namie, 2000): 1) reduction in efficiency and productivity, 2) deterioration in the quality of service, 3) low worker satisfaction and decreased loyalty to the institution (Zapf et al., 1996), 4) adverse publicity, 5) legal costs, 6) absenteeism, sick leave and high turnover (Leymann, 1996; Rayner, 1997). There has been much discussion about the symptoms of those who suffer this type of abuse (Brodsky, 1976; Einarsen et al., 1994; Mikkelsen \& Einarsen, 2001) and the psychosomatic and psychological stress (Niedl, 1995) and physical consequences of the abuse (Groeblinghoff \& Becker, 1996).

The police have a socially isolated organization that is resistant to changes and has a strong internal culture (as learned and shared norms of behavior -Austin \& Jackson, 1997). They are accustomed to codes of silence and secrecy that develop an ethos based on the daily policing experience and a strong socialization process for new members (Brown \& Campbell, 1994; Van Maanen, 1975: 207). Similar to other institutions, on an administrative and management level, the police develop strategies to achieve their objectives, and bullying is often tolerated as a police strategy (Rayner, 2000: 19). Other factors in the organization may increase the possibility of bullying as an accepted practice within the institution (Beck \& Wilson, 2000: 132). A task-oriented leadership style based on bullying (Vartia 1996), or at least allowing it, has serious consequences for the general performance of the police organization and, in particular, the victims (Hoel \& Salin 2003). Several coping strategies are used, and these can be categorized into several forms (passive vs. active dimension: Ölafsson \& Jóhannsdóttir (2004); representative organisational responses: Ferris (2004); problem/emotion focused: Aquino \& Thau (2009)).

\section{METHODOLOGY}

This study explores the subjective perceptions of high-, middle- and low-ranking personnel through the use of qualitative research techniques (interviews and ethnography). Special attention was paid to crossreferencing lower-raking officials with higher-ranking officials.

\subsection{In-Depth Interviews}

\section{A. Participants and Procedures}

After permission was obtained for the study, police officers from the Secretary of Public Security for Mexico City were contacted to be interviewed at the workplace directly by the author and a team of interviewers using the network sampling or snowballing technique (Frey et al., 2000). The interviews were conducted in all Mexico City police stations. The police who were interviewed varied in age (30 - 55 years), gender (78 male and 12 female, but no differences were found between the responses of men and women concerning freezing) and incomes. All were born in Mexico, but $18 \%$ were Hispanic and $82 \%$ mixed race (mestizos). All had at least five years experience in 
their job, and their income was dependent upon their rank within the organization. In total, 125 policemen were contacted, with a response rate of $72 \%$. Thirty subjects were interviewed for each of the low-, middleand high-ranking levels. Of the respondents, 32\% believed that they were victims of bullying or exposed to it for at least 6 months (Mikkelsen \& Einarsen, 2001).

\section{B. Data Collection Instruments}

A somewhat structured interview was used that included open and closed questions on the following topics: 1) socioeconomic level, 2) education, 3) work history, 4) work routine, 5) training, 6) worker satisfaction, 7) incidence of discrimination and 8) bullying. Questions arose from these topics, but the final protocol was modified by adding or removing questions according to the quality of information provided by the interviewee. Each interview was recorded and transcribed. The interviews lasted between 25 and 90 minutes, with an average time of 45 minutes. The interviews were made with particular regard to the rights and protection of the participants, including reducing the risk of unanticipated harm, protecting the interviewee's information, effectively informing interviewees about the nature of the study, and reducing the risk of exploitation (DiCicco-Bloom \& Crabtree, 2006). An informed consent was requested.

\section{Data Analysis}

Data analysis was developed by means of multiple reviews of the transcribed interviews (Miles \& Huberman, 1994):

1. The corresponding narrations on each of the topics were classified and transferred to a thematic file (Kellehear, 1993).

2. The subthemes that were identified within each topic were developed in detail and codified.

3. Two complementary strategies were used to represent the experiences of the police, as follows: a) a vision of consensus through the interviews and b) a perspective of variability through the responses provided in the interviews.

4. Finally, patterns were identified from cross-cases to carefully analyze the patterns in the perceptions of freezing and the behavioral strategies used to cope with it.

\subsection{Ethnographic Work}

The goal was to identify patterns of bullying in the in-depth interviews with the Mexico City police. For the ethnographic analysis, direct and systematic observations were made concerning the practices and routines of the police in a specific time and place, often involving their direct intervention (Brewer, 2000: 59). There was participative involvement in the daily lives of the police for a specific time (6 months) that included observing their actions, listening to their conversations with colleagues, formulating questions and recollecting available data that could generate information (Hammersley \& Atkinson, 1995, Walsh, 2000: 226). The research questions addressed freezing and the cultural perception of it. If institutional methods and regulations exist that homogenize police activities, specific patterns of conduct are certainly delineated (Duneier, 1999; Salvador et al., 1999; Newman, 1999). The ethnographic study included a series of open and spontaneous interviews with 30 police officers in active service on the streets. This information was contrasted with the qualitative in-depth interviews.

\section{CONTEXT RESEARCH}

This work focuses on a specific case under study: the police of Mexico City that are in charge of all the police activities in the city excepting the investigation of crimes (Mexican Constitution, 2009: art. 21). This institution is divided into the following areas of activity: 1) Citizen Protection Units (CPU), 2) Industrial Bank Police (IBP), 3) Backup Police (BP), 4) Special Forcescanines $(C), 5)$ Auxiliary Police $(A P)$, including the Metropolitan Police, which are divided into a) Feminine Police (FP), b) Mounted Metropolitan Police (MMP), c) Metropolitan Protest Police (MPP), d) Metropolitan Police-Special Force (SF), which in turn is subdivided into i) Riverside Police (RP), ii) Helicopters (H), iii) Radars (R) and iv) Tow Trucks (TT).

There are the usual differences in rank (from police to commissioner) and patterns of command of a police institution. The managers in command, middle managers, and subordinate officers received training in use of force, human rights and administrative procedures but not in personnel management. Contrary to others Police departments in the world that tend to be very formal managing internal problems, the case in Mexico City is right the opposite, because of its scant professionalization (the use of scientific methods of police work), the lack of a professional police management system and citizens' lack of monitoring. 
This situation has made the police hyper-develop its informal system to manage internal conflicts.

Mexico has the largest police force in Latin America in terms of numbers and funding. The value of analysing the Mexican Police and the possible uses of the data obtained lies in that there is no previous study in the country and it can be used to better understand other cases. The findings on the "freezing out" of the police in Mexico City can reveal much about the police management in other parts of the world, specially in Latin America.

\section{RESULTS}

\subsection{Freezing out within the Police Force of Mexico City}

Although bullying appears in the interviews in its complete form, all of its facets will not be addressed here. Only one type of work harassment was studied (freezing). The other factors of bullying were excluded from the analysis, including conflict of rumors, public humiliation, useless and repetitive tasks, and access restriction to certain places within the institution or to the equipment necessary for carrying out one's duty. This exclusion was performed because no significant differences in cultural perceptions and responses were found for these factors in the Mexican police force, which contrasts the findings of international studies (Thacker, 1996; Zapf \& Gross, 2001; Ölafsson \& Jóhannsdóttir, 2004).

In the Mexican police force, freezing is considered as an extended and easy method of handling a conflict or punishing an individual (as a micro-political behavior in the organization, Zapf \& Einarsen, 2003, or as organizational culture, Dejours, 1993; Hoel \& Salin, 2003). As a high-ranking official in the AP affirmed: "You leave them with nothing to do for a while, you put them in the fridge and they understand that they messed up without having to tell them anything. You don't have to fight: they understand." The avoidance of an open conflict, freezing is an emotionally and institutionally cheap way for medium- and high-ranking officers to resolve conflicts and, at the same time, set limits on the actions of the subordinate. If the conflict is not exposed, the freezing victim cannot defend himself, argue or criticize the accuser, appeal to a superior or complain or protest in any internal or external context. This is one of the most brutal characteristics of freezing, as the victim is defenseless and must address the effects of the conflict alone. It places work relations in a closed context, beyond friendship or circumstantial relationships. In addition to direct freezing, there are ways to indirectly freeze the activities of subordinates or their activities. However, these methods are not strictly freezing (as described here); rather, they are an isolation or exclusion (Leymann, 1992; Niedl, 1995; Vartia, 1993; Zapf et al., 1996):

1. Training: excluding an agent from training is one of the most effective indirect ways to relegate work or remove the agent from the normal activities of his work group.

2. Group Meetings: another way of exclusion is not inviting or informing an agent about certain group meetings where important decisions are made or operative strategies are defined.

3. Group Communication: Finally, there is the exclusion from meetings where information is divulged about the future of the group or the integrants of the institution in general. This type of meeting is particularly delicate because the lack of this information can directly affect the behavior of the excluded agent.

Such practices are relatively common in the police force in Mexico City, and the victims are frequently in the lower ranks of the institution because they are most vulnerable (Hoel \& Cooper, 2000: 26, Segurado Torres et al., 2008: 741; Rayner, 2000). According to the agents, these practices are accompanied by other organizational characteristics that help to aggravate the exclusion (as a consequence of freezing):

a) Red Tape for filing complaints.

i In Mexico City's police force, there is no authentic channel for complaints; therefore, there is no formal process for registering a complaint. All of the interviewed police stated that the only complaints are external, coming from people who report crimes, victims of crime, detained individuals or their families. The police do not even consider subordinates as able to register complaints (there are no unions or police ombudsmen). They do not have the right to complain unless there is a flagrant violation of their rights. A mid-ranking official from the MMP explained the following: "Well, they already have a job, don't? If no one does anything to them, why should they complain? All they have to do is work". Midand high-ranking officers tend to 
underestimate the stress factors in the police work conducted by the lower ranks, even the most psychologically traumatic work such as risking their lives, intervening in conflicts, using force, shiftwork, etc. (Crank et al., 1993; Davis, 1993; Savery et al., 1993; Reinecke et al., 2007).

An important explanation for the lack of a formal complaint process is the lack of trust in worker relations. Motivated by this, all complaints and protests from a subordinate generate suspicion. A high-ranking official in the AP affirmed: "They only come to me to ask for something: they don't know how to do anything else. If it isn't more vacation time (...), less workload or more days off or something (...). They never come to me to ask for more work." According to this, the complaints never contain valuable information that could help improve internal organizational processes. They are viewed merely as attacks against the organization or someone in it.

The second cause is related to the lack of formality in social relations in the city and country or the absence of judicial institutions that oversee worker relations. This entails the lack of formal mechanisms to manage the organizational process. All issues are resolved through personal relationships. An agent for the CPU stated, "When I have a problem, I go see my boss and I ask him for a favor (for his help). That is why you need to keep a good relationship (with them), because if you act stupid, they won't help (you)."

iv At the same time, freezing cannot be channeled in the way of traditional complaints. As an agent of the BP stated: "And what are we going to say? That they don't give us anything to do? You don't complain about that. I can't go and say that I don't have anything to do or that the boss doesn't want to give us work." Freezing is an ideal way to punish an individual because it is institutionally incommunicable and can only be discussed within the solidarity of tight-knit groups.

b) Worker satisfaction. i There are no regular, formal measurements of worker satisfaction in the police institutions that were analyzed. The statements of the commanders that were interviewed are quite revealing. A chief in the BP affirmed: "It's subjective. It is seen in worker performance, in their faces."

ii As in the previous case, the lower ranks of the police institutions view this as the administration's disinterest in their needs. An agent from the IBP stated: "They don't pay attention to us even if we have something to say about the job. They think that we can't know anything or that we can't know more than they do. (They think) we don't have anything to say even if the new (boss) is really young and you have been working here for more than 20 years." This lack of interest from the police organization directly affects the job commitment and worker satisfaction of lower-ranked officers (Brunetto \& FarrWharton, 2003).

\subsection{Coping Strategies}

Based on the subjective perceptions of this type of bullying, which depend on the varying ranks in the organizational structure, different strategies for coping are formed (Einarsen et al., 2000; Salmivalli et al., 1996; Lee \& Brotheridge, 2001). The middle ranks opt to make their bosses fire them or quit, as a female officer from the FP indicated: "They aren't going to treat me like that. I can do a job well; if not, I'm leaving. I have other places where I can work." Meanwhile, the lower ranks (in lower economic standing) elaborate diverse methods to avoid quitting, as an agent in the BP suggests: "I am not leaving. Even if they make me sit and stare at the wall all day, l'll stare at it with pleasure (...). I have to bring home the bacon (...); but when they don't want to give me any (work), I look for something to do (...), even if it is cleaning. I'm not worthless, you know?"

As evident in the literature above, there are several coping strategies. However, a simple model is selected to show the most common strategies that emerged in the interviews by rank:

1. Exit-used, for instance, by middle-rank officers (Cox, 1987; Keashly et al., 1994; LutgenSandvik, 2006). 
2. Searching for alternative solutions-used, for instance, by low-rank officers.

a. Seeking help from others (to solve the problem).

i. Inventing tasks. In general, for economic reasons (Hirigoyen, 2001) rather than the perception of freezing as a strategy for expulsion (Dejours, 1998), they generate the need for a new task, such as recuperating or updating a procedure that has fallen into disuse.

ii. Delegating responsibilities. Another way to avoid freezing is to seek solidarity amongst colleagues to receive tasks from them. In this way and in benefit to both parties, some policemen become secretaries for others of their same rank. One rids himself of responsibilities that he considers undesirable while the other performs work that is meaningful for the institution, as a secretary in the IBP stated: "When the boss doesn't pay attention to me, I get work from the afternoon secretary so I don't end up with nothing to do." (Here "get" is intended to suggest collaboration, reducing the workload of a colleague.)

iii. Alternative channels of information. When the agents are excluded from informative meetings that directly affect them, they seek information from other close colleagues in exchange for favors or to show solidarity. An agent from the FP stated: "I find out just the same. I look for my friend (we've been doing it for years; she's the godmother of my child). She tells me."

iv. Informal intervention. On some occasions, there are informal bosses or other agents with authority that act as intermediaries or conflict resolvers between the administration and the lower ranks. The agents affected by freezing can request intervention as a solution to the conflict or at least as an indirect means of seeking the group's help. One BP agent declared: "In a problem like this, I look for my buddy because he is from the previous administration and even the main boss listens to him."

b. Avoidance (Djurkovic et al., 2005).

i. Sickness. This is one of the most common methods that agents use in combination with others. They attempt to appear sick most of the time and obtain the longest sick leave allowances possible (Zapf \& Gross, 2001).

ii. Leave of absence. Victims attempt to obtain a paid leave of absence (Zapf \& Gross, 2001).

iii. Commissions. Victims attempt to find commissions to carry out activities outside of the institution, for example, messengers, mail carriers, transport, moving prisoners, etc. An agent from the AP indicated: "I do whatever I have to to not be there: anything. There are always things to do and places to go. Because if you stay, you lose."

iv. Change of position. They try to change positions or activities within the institution, another branch or a similar institution tied to the previous one (Zapf \& Gross, 2001).

v. Retirement. If it is possible, one can request early retirement or retirement in advance (Zapf \& Gross, 2001).

c. Hiding (either in the office or outside).

i. Hiding in offices or other places within the institution with friends and occasionally carrying out a task, for example, catering to the friends' needs. According to an agent of the BP: "I hide in a (cave) with the oldest ones that already know me. Nothing bad happens; I make them coffee and help with something so I can stay. Then, I show up (at my position) after midday when (my boss) has already gone."

ii. Confronting the inability to hide outside of the office, the agent hides inside the office and behaves as if he had work to accomplish and responsibilities to address. An agent of the MMP detailed: "It never happened to me, but several times I 
saw when they were acting, when there is nothing to do: arranging papers, looking in drawers, moving around the place with papers in their hands (...)."

\subsection{The Perception of Freezing According to the Victim'S Position}

As was previously observed, the perception of freezing and the meaning that victims attach to this experience differ by rank within the police hierarchy:

- $\quad$ Middle-ranking officials perceive freezing as a gentle strategy for eliminating personnel without much cost to the institution (Einarsen et al., 1994), from internal punishments to personal vengeance. A mid-ranking official from the CPU argued: "If they want to get rid of me, fire me with all the (legal benefits) and pay me what I am supposed to get."

- $\quad$ The lowest-ranking officials do not consider it as a strategy for cutting personnel (or to protect an institutional interest, Zapf \& Einarsen, 2003), but as a form of social discrimination. An agent from the SP affirmed: "They leave me out because of who I am, not because I do (my work) poorly, but because I am not like them. But, it isn't my fault; I can't be what I am not if I wasn't born that way."

In general, bullying directly affects the self-esteem of the victim and the acknowledgement of others. Its effect is linked to the victims' self-perception, social role, place in the work environment, economic status and acknowledgement (Tersptra \& Baker's, 1991; Agervold, 2007). It also acts in a different manner according to the individual's ability to reinsert himself into the labor structure or to place the current labor situation at risk. With higher self-esteem, acknowledgement, economic status and less risk, the vulnerability decreases (although Parkins et al. (2006) believe that self-esteem is not related to workplace bullying). Thus, the perception may differ in the mid and low ranks. Both groups discuss freezing with dignity and with an awareness of themselves, but the middle ranks generated aggression against the abuser. In the low ranks, blame and resentment against themselves and their work group resulted due to the lack of solidarity and support (Escartín et al., 2011). The strategy in the middle ranks consists of using aggression to defend oneself from aggression or retiring and receiving the greatest economic benefit possible (Lutgen-Sandvik, 2006). There may be hierarchical differences between the abuser and the victim, but this does not translate into pronounced socioeconomic differences between them. In the lower ranks, individuals defend themselves by hiding or escaping from aggression. They do not feel that they are in the position to confront the aggressor because they are in different levels of the organization, with asymmetrical powers and qualifications and a different educational and social standing (low class).

\section{DISCUSSION}

\subsection{The Cultural (Mexican) Perception}

One of the more prominent peculiarities of freezing lies in that it is never explicit. A high-ranking officer in the CPU indicated that things are not "said", the conflict cannot be proven. For example, the boss does not warn the subordinate that he will not be given specific responsibilities or will be marginalized from his group's activities. Thus, freezing has a disturbing effect not only on the victim, but also for those surrounding him. The general reaction of the group is the fear of also being frozen due to closeness, friendliness or solidarity with the victim. At the same time, because it is not an open conflict, suspicion is immediately directed towards the victim in regards to the cause of the conflict. The following characteristics (from the interviews) can also be added to this data:

1. Because it is not explicit, an integral resolution of the conflict is hindered.

2. The victim cannot apologize or explicitly address the problem because he may not necessarily know the cause of the problem, as he was not warned or informed about it. You cannot solve a problem that apparently does not exist.

3. There is no formal punishment, no established outcome.

4. The victim does not know when the freezing will end; for example, if it will lead to direct harassment or if an agreement will be reached by both parties involved.

As noted, the characteristics of freezing affect the group that reacts to the threat in different ways ("ripple effect": Rayner, 1999). When the group shows fear toward the punishment and suspicion toward the victim, the group treats the victim in a way that is similar to discrimination; they isolate, marginalize and reject him. 
A possible explanation of why freezing is viewed as social discrimination is that the consequences are similar to the social discrimination of the group. The data indicate that freezing (similar to other forms of bullying) an agent does not necessarily arouse the solidarity and support of the group in the same rank (there could be several bystander responses to the bullying: Hoel et al., 1999; Rayner, 1999). Many times, freezing from a superior is accompanied by the abandonment of the group (Namie \& Namie, 2000). This can occur for several reasons (emerging from the interviews), as follows:

1. Colleagues use this situation to get revenge during their partner's fall from grace.

2. Colleagues use the opportunity to gain rights, vacant positions or sinecures within the institution (in highly territorial organizations).

3. They distance themselves because they fear the possible contaminating effect of freezing.

4. They do not want to appear involved in a conflict that is not theirs and can bring negative consequences.

5. To summarize, no one knows, recognizes or can predict when or how the conflict will end or the possible indirect consequences.

However, the repercussions of the conflict are similar to those of the direct social discrimination from the group, i.e., isolation, marginalization, rejection and others. But, is freezing a form of discrimination in the police force of Mexico City? It is difficult to determine the answer to this question because aggressors were not interviewed. However, it is possible that freezing is not a direct discrimination (solely a punishment), although it could be culturally perceived as such. Likewise, it can be founded on discriminatory criteria (CDHEM, 2008). In this case, the second reason why lower income agents perceive the aggression of worker abuse as a form of discrimination is because they are in a lower social position than the aggressor and link this particular type of aggression to the aggressive social discrimination that they suffer in their daily lives outside of the workplace. From their perspective, freezing becomes another form of social discrimination from the most comfortable sectors of society (Conapred, 2004). An agent of the Protest Police (MPP) affirmed: "They look at you the same way as (they do) when you are waiting for the bus and they are passing by in their expensive trucks."
Another reason to consider freezing as a type of discrimination in the police force of Mexico City is that it is not a new social practice. In the Mexican social context, a type of freezing or void is common in relationships between groups that occupy different socioeconomic levels. It is a type of social relationship itself. Ignoring individuals when they talk, ask a question, or make a complaint or request represents the attempt to communicate the desire to reestablish a social distance. Social freezing is a procedure that is used to inform an individual who he does not belong to the same social group and, therefore, the relationship cannot be direct or open. In the view of the aggressor, a serious mistake in protocol has been committed by jumping social barriers with direct communication. The aggressor's response is silence as a lack of respect or as a disregard for the other's needs and attempt at communication (CDHEM, 2008, 121). The relationship is "frozen". In these situations, the one who is in the more favorable socioeconomic level behaves as if the other had not spoken or does not exist because, in fact, he does not exist in the eyes of the aggressor's social group. The victim becomes invisible, and this "invisibility of the servant" is an extended social practice throughout the country (Hopenhayn \& Bello, 2001). Thus, people from low-income sectors perceive this case of bullying as an extension of social freezing in the workplace. Certain stereotypes and social behaviors are repeated at work.

At the same time, low-income sectors use social freezing on some occasions, repeating the model from other social groups. They may do so with various motives:

- $\quad$ As a means for excluding members of the same social group or one that is considered inferior (Shallcross et al., 2008: 62).

- As a means of defense.

This last way to use freezing or void can have several meanings or explanations, but these relationships are generally between different social groups when a member of the higher group address to a member of the lower group. In this case, the person (lower group) can resort to silence for the following reasons:

- He/she does not know how to behave in the situation

- He/she made a mistake and is attempting to avoid punishment 
- $\quad \mathrm{He}$ she does not understand the talking point

- He/she fears making a mistake and being punished

- $\mathrm{He}$ she fears the negative reaction of the other person

\section{- $\quad \mathrm{He} / \mathrm{she}$ desires to avoid conflict}

In Mexico, freezing is used by all social groups to avoid the escalation of interpersonal conflict or directly avoid the problem. In the national culture, there is a true horror conflictui that impedes the compromised individual from openly and directly dealing addressing the conflict with the other person (Bonfil, 1991). Because there are no formal and productive conflict resolution mechanisms, the possibility of efficient judicial processes does not exist, not even in a strong state of law or a civic culture of non-violent and productive conflict resolution and respect to all human rights. The social groups have developed mechanisms to omit conflicts, and freezing is one of the most important mechanisms. At the same time, violence appears in the national culture as an acceptable method of solving problems (Agoff et al., 2013) and settling conflicts that likely originated in the history and traditions of the country (Tutino, 1986). In a culture in which violence appears possible and on the near horizon social procedures are not standardized, individuals avoid other people with silence or freezing because they sense that once conflict begins, escalation can be irremediable, unstoppable and result in violence.

\section{CONCLUSION}

The current paper attempted to characterize the most extended form of bullying (freezing) and the coping strategies in the police workplace of Mexico City and examine how the national and police culture influence the victim's perception of it. In this study, the social, organizational and cultural determination of the victim's perception is emphasized and the most psychological explanations or considerations of the phenomenon are not addressed (such as character analysis of the perpetrator or the target, Namie \& Namie, 2000; Lewis \& Orford, 2005, or the social effects, Arnetz \& Arnetz, 2001). As previously shown, freezing (leaving a subordinate without instructions) is perceived by the victims as social discrimination because it is similar to the social discrimination that they suffered in daily life. This could be a test for the negotiation theory that is used to explain the various ways that conflict is handled depending on the cultural orientation of the people involved (Ting-Tommey \& Otzel, 2001) and Hofstede's cultural model (2001), which offers a framework to analyze national cultural differences (individualism/collectivism, long-term/shortterm orientation, etc.). In fact, the Mexican case (freezing) suggests that the best way (and perhaps the only way) to explain how the victims address bullying is by studying the social and institutional culture. The view of freezing as a structural problem is not sufficient to understand the victim's reaction and the normal operation of the Mexican police (for example, inventing tasks). Freezing takes place within a (police) culture of mistrust, where the management of conflicts is practically nonexistent or takes place in a destructive manner. There is no real dialogue about or communication of differences, no channels of complaint to follow, and no one to listen because the freezing process cannot be discussed. This coincides with an organizational culture in which personal relationships are important, e.g., if one has a good relationship with his/her superior, then all is well. In addition, the culture is hierarchical; thus, only the boss's opinion is important. Here, the link between Mexican culture in general and the police culture is evident and important.

In terms of conflict theory (Zapf \& Gross, 2001), this case of bullying (freezing) signifies an "unsolved social problem or conflict" that reaches a superior level of escalation at the workplace. The institution can develop a legal instrument to prevent such bullying, but the real solution is eliminating the discrimination from the Mexican society.

\section{REFERENCES}

Agervold, Mogens 2007. "Bullying at Work: a Discussion of Definitions and Prevalence, Based on an Empirical Study." Scandinavian Journal of Psychology 48, 2: 161-172. http://dx.doi.org/10.1111/j.1467-9450.2007.00585.x

Agoff, Carolina, Irene Casique and Roberto Castro. 2012. Visible en Todas Partes. Estudios sobre Violencia contra Mujeres en Múltiples Ámbitos. México: UNAM (in press).

Aquino, Karl and Stefan Thau. 2009. "Workplace Victimization: Aggression from the Target's Perspective." Annual Review of Psychology 60: 717-741. http://dx.doi.org/10.1146/annurev.psych.60.110707.163703

Austin, Michael and Erwin Jackson. 1997. "Occupational Mental Health and the Human Service: A Review." Health and Social Work 2: 92-118.

Ayoko, Oluremi, Victor Callan and Charmine Hartel 2003. "Workplace Conflict, Bullying, and Counterproductive Behaviours." International Journal of Organizational Analysis 11, 4: 283301.

http://dx.doi.org/10.1108/eb028976 
Baillien, Elfi, Inge Neyens and Hans De Witte 2008. "Organizational, Team Related and Job Related Risk Factors for Bullying, Violence and Sexual Harassment in the Workplace: A Qualitative Study." International Journal of Organisational Behaviour 13, 2: 132-146.

Baillien, Elfi, Inge Neyens and Hans De Witte. 2009. "Why is Organizational Change Related to Workplace Bullying? Role Conflict and Job Insecurity as Mediators." Economic and Industrial Democracy 30, 3: 348-371. http://dx.doi.org/10.1177/0143831X09336557

Björkqvist, Kaj, Karin Österman and Monika Hjelt-Bäck. 1994. "Aggression among University Employees." Aggressive Behavior 20, 3: 173-184. http://dx.doi.org/10.1002/1098-2337(1994)20:3<173::AIDAB2480200304>3.0.CO;2-D

Bowling, Nathan and Terry Beehr. 2006. "Workplace Harassment from the Victim"s Perspective: A Theoretical Model and Meta-Analysis." Journal of Applied Psychology 91, 5: 9981012. http://dx.doi.org/10.1037/0021-9010.91.5.998

Bonfil Batalla, Guillermo. 1991. México Profundo: Una Civilización Negada. México: Alianza.

Brewer, John. 2000. Ethnography. Buckingham: Open University Press.

Brodsky, Carroll. 1976. The Harassed Worker. Lexington: Lexington Books.

Brown, Jennifer and Elizabeth Campbell. 1994. Stress and Policing: Sources and Strategies. West Sussex: Wiley.

Brunetto, Yvonne and Rod Farr-Wharton. 2003. "The Commitment and Satisfaction of Lower-Ranked Police Officers: Lessons for Management." Policing: An International Journal of Police Strategies \& Management 26, 1: 43-63. http://dx.doi.org/10.1108/13639510310460297

CDHEM. 2008. Un Acercamiento a la Discriminación. De la Teoría a la Realidad en el Estado de México. México: Comisión de derechos humanos del Estado de México.

Conapred. 2004. Prohibido Discriminar. México: Consejo Nacional de Prevención de la Discriminación.

Cox, Helen. 1987. "Verbal Abuse in Nursing: Report of a Study." Nurse Management 18: 47-50. http://dx.doi.org/10.1097/00006247-198711000-00015

Crank, John, John Hewitt, Robert Regoli and Robert Culbertson. 1993. "An Assessment of Work Stress among Police Executives." Journal of Criminal Justice 21: 310-21. http://dx.doi.org/10.1016/0047-2352(93)90016-G

Dejours, Christophe. 1993. Travail Usure Mentale. Paris: Bayard.

Dejours, Christophe. 1998. Souffrance en France. Paris: Seuil.

DiCicco-Bloom, Barbara and Benjamin Crabtree. 2006. "The Qualitative Research. Interview." Medical Education 40, 4: 314-21.

http://dx.doi.org/10.1111/j.1365-2929.2006.02418.x

Dick, Gavin. 2008. The Influence of Managerial Factors on Bullying in the Police, working Paper, 179, University of Kent, Kent of Business School, December, available at: http://www.kent.ac.uk/kbs/pdf/Gavin-Dick-No-179.pdf (accessed 08.26.09)

Di Martino, Vittorio, Helge Hoel and Cary Cooper. 2003. Preventing Violence and Harassment in the Workplace. Bruxelles: European Foundation for the Improvement of Living and Working Conditions.

Djurkovic, Nikola, Darcy McCormack and Gian Casimir, G. 2005. "The Behavioral Reactions of Victims to Different Types of Workplace Bullying." International Journal of Organization Theory and Behaviour 8: 439-460.

Duneier, Mitchell. 1999. Sidewalk. New York Farrar: Straus \& Giroux.

Einarsen, Stäle, Inge Raknes and Stig Berge Matthiesen. 1994. "Bullying and Harassment at Work and their Relationships to
Work Environment Quality: An Exploratory Study." European Work and Organizational Psychologist 4, 4: 381-401. http://dx.doi.org/10.1080/13594329408410497

Einarsen, Stäle and Anders Skogstad. 1996. "Bullying at Work: Epidemiological Findings in Public and Private Organizations." European Journal of Work and Organizational Psychology 5, 2: 185-201. http://dx.doi.org/10.1080/13594329608414854

Einarsen, Stäle. 2000. "Harassment and Bullying at Work: A Review of the Scandinavian Approach." Aggression and Violent Behavior 5, 4: 371-401. http://dx.doi.org/10.1016/S1359-1789(98)00043-3

Ferris, Patricia. 2004. "A Preliminary Typology of Organisational Response to Allegations of Workplace Bullying: See No Evil, Hear No Evil, Speak No Evil." British Journal of Guidance \& Counselling 32, 3: 389-395. http://dx.doi.org/10.1080/03069880410001723576

Escartín, Jordi, Dieter Zapf, Carlos Arrieta and Álvaro RodríguezCarbelleira. 2011. "Worker's Perception of Workplace Bullying: A Cross-Cultural Study." European Journal of Work and Organizational Psychology 2: 178-250. http://dx.doi.org/10.1080/13594320903395652

Frey, Lawrence, Carl Botan and Gary Kreps. 2000. Investigating Communication: An introduction to research methods. Needham Heighs, MA: Ally \& Bacon.

Groeblinghoff, Dieter and Michael Becker. 1996. "A Case of Study of Bullying and the Clinical Treatment of Bullying Victims." European Journal of Work and Organizational Psychology 5 , 2: $277-294$. http://dx.doi.org/10.1080/13594329608414859

Hammersley, Martyn and Paul Atkinson. 1995. Ethnography: Principles in Practice. London and New York: Routledge.

Hartig, Kate and Jeannene Frosch. 2006. "Workplace Mobbing Syndrome: The Silent and Unseen Occupational Hazard." National Conference on Woman and Industrial Relations (NCWIR), Griffith University, 12-14 ${ }^{\text {th }}$ July, Brisbane: http://www.qwws.org.au/filestore/OWOL\%20Papers/PDF/Har tig\%20and\%20Frosch\%20paper\%20FINAL.pdf (accessed 10.09.09).

Hauge, Lars Johan, Anders Skogstad and Stäle Einarsen. 2007. "Relationships between Stressful Work Environments and Bullying: Results of a Large Representative Study." Work \& Stress 21, 3: 220-242. http://dx.doi.org/10.1080/02678370701705810

Hirigoyen, Marie France. 2001. Malaise dans le Travail. Harcelement Moral, Demeler le Vrai du Faux. Paris: Syros.

Hoel, Helge and Cary Cooper. 2000. Destructive Conflict and Bullying at Work. Manchester: University of Manchester.

Hoel, Helge, and Denise Salin. 2003. "Organisational Antecedents of Workplace Bullying." Pp. 203-218 in Stäle Einarsen, Helge Hoel, Dieter Zapf, and Cary Cooper (eds.) Bullying and Emotional Abuse in the Workplace. International Perspectives in Research and Practice. London: Taylor \& Francis.

Hofstede, Geert. 2001. Culture's Consequences: Comparing Values, Behaviors, Institutions, and Organizations across Nations. Thousand Oaks: Sage.

Hogh, Annie and Andrea Dofradottir. 2001. "Coping with Bullying in the Workplace." European Journal of Work and Organizational Psychology 10, 4: 485-495. http://dx.doi.org/10.1080/13594320143000825

Hopenhayn, Martín and Alvaro Bello. 2001. Discriminación Étnico Racial y Xenofobia en América Latina y el Caribe. Santiago: Cepal.

Keashly, Loraleigh, Virginia Trott and Lynne MacLean. 1994. "Abusive Behavior in the Work-Place: A Preliminary Investigation." Violence and Victims 9, 4: 341-357. 
Kellehear, Allan. 1993. The Unobtrusive Researcher. St. Leonards: Allen and Unwin.

Knorz, Carmen and Dieter Zapf. 1996. "Bullying-Eine Extreme Form Sozialer Stressoren am Arbeitsplatz." Zeitschrift für Arbeits\& Organisationspsychologie 40: 12-21.

Lee, Raymond and Céleste Brotheridge. 2006. "When Prey Turns Predatory: Workplace Bullying as a Predicator of Counteraggression/Bullying, Coping, and Well-Being." European Journal of Work and Organizational Psychology 15, 33: 352-377.

http://dx.doi.org/10.1080/13594320600636531

Lewis, Sian and Jim Orford. 2005. "Women's Experiences of Workplace Bullying: Changes in Social Relationships." Journal of Community \& Applied Social Psychology 15, 1: 29-47. http://dx.doi.org/10.1002/casp.807

Leymann, Heinz. 1992. "Vuxenmobbing på Svenska Arbetsplastser. En Rikstäckande Undersökning Med 2.438 Intervjuer. Delrapport 1 [Mobbing at Swedish workplaces 1st Report]." Arbetarskyddsstyrelsen, Stockholm.

Leymann, Heinz. 1996. Bullying. La Persecution au Travail. Paris : Du Seuil.

Lutgen-Sandvik, Pamela. 2006. "Take this Job and...: Quitting and Other Forms of Resistance to Workplace Bullying". Communication Monographs 73, 4: 406-433. http://dx.doi.org/10.1080/03637750601024156

Lynch, Jessica. 2002. Workplace Bullying: Implications for Police Organizations. Paneyham: Australasian Centre for Policing Research.

McCarthy, Paul, Michael Sheehan and Rachael Kearns. 1995. Managerial Styles and their Effect on Employees' Health and Wellbeing in Organizations Undergoing Restructuring. Brisbane: Griffith University.

Mikkelsen, Eva Gemzöe and Stig Berge Einarsen. 2001. "Bullying in Danish Work-Life: Prevalence and Health Correlates." European Journal of Work and Organisational Psychology 10, 4: 393-413. http://dx.doi.org/10.1080/13594320143000816

Miles, Matthew and Michael Huberman. 1994. Qualitative Data Analysis: An Expanded Sourcebook. Newbury Park: Sage.

Namie, Ruth and Gary Namie. 2000. The Bully at Work: What You Can Do to Stop the Hurt and Reclaim your Dignity on the Job. Benicia, CA: Sourcebooks.

Newman, Katherine. 1999. No Shame in my Game: The Working Poor in the Inner City. New York: Knopf \& Sage.

Niedl, Klaus. 1995. Mobbing/Bullying at the Workplace. Munich: Rainer.

Nielsen, Morten, Stig Berge Mattiesen and Stäle Einarsen. 2004. "When the Bully is a Leader: The Relationship between Destructive Leaders and Symptoms of Posttraumatic Stress Disorder among Victims of Workplace Bullying." Paper presented to the Fourth International Conference on Bullying and Harassment in the Workplace, Bergen, 125-127.

Ölafsson, Ragnar and Hanna Jóhannsdóttir. 2004. "Coping with Bullying in the Workplace: The Effect of Gender, Age and Type of Bullying." British Journal of Guidance \& Counselling 32, 3: 319-333.

http://dx.doi.org/10.1080/03069880410001723549

Paoli, Pascal and Damien Merllié. 2001. Third European Survey on Working Conditions 2000. Luxembourg: Office for Official Publications of the European Communities.

Parkins, Irina, Harold Fishbein and Neal Ritchey. 2006. "The Influence of Personality on Workplace Bullying and Discrimination." Journal of Applied Social Psychology 36: 2554-2577. http://dx.doi.org/10.1111/j.0021-9029.2006.00117.x

Randall, Peter. 1997. Adult Bullying: Perpetrators and Victims. London: Routledge.
Rayner, Charlotte. 1997. "The Incidence of Workplace Bullying." Journal of Community and Applied Social Psychology 7: 199208.

http://dx.doi.org/10.1002/(SICI)1099-

1298(199706)7:3<199::AID-CASP418>3.0.CO;2-H

Rayner, Charlotte. 1999. "From Research to Implementation: Finding Leverage for Prevention." International Journal of Manpower 20: 28-38. http://dx.doi.org/10.1108/01437729910268614

Rayner, Charlotte. 2000. Bullying at Work. Stafford: Staffordshire University Business School.

Rayner, Charlotte, Helge Hoel and Cary Cooper. 2002. Workplace Bullying: What Do We Know, Who is to Blame and What Can We Do? New York: Taylor \& Francis.

Reinecke, Stefan, Bernd Runde, Frauke Bastians, Udo Weiss, Gereon Heuft and Olaf Bär, O. 2007. "Quality of Psychological Strain in Police Work. Development of a Taxonomy of Sources of Stress." Zeitschrift für Psychosomatische Medizin und Psychotherapie 53, 1: 42-52.

Salin, Denise. 2003a. "The Significance of Gender in the Prevalence, Forms and Perceptions of Workplace Bullying." Nordiske Organisasjonstudier 5, 3: 30-50.

Salin, Denise. 2003b. "Ways of Explaining Workplace Bullying: A Review of Enabling, Motivating and Precipitating Structures and Processes in the Work Environment." Human Relations 56, 10: 1213-1232. http://dx.doi.org/10.1177/00187267035610003

Salmivalli, Christina, Jarkko Karhunen and Kirsti Lagerspetz. 1996. "How do the Targets respond to Bullying?" Aggressive Behavior 22: 99-109. http://dx.doi.org/10.1002/(SICI)10982337(1996)22:2<99::AID-AB3>3.0.CO:2-P

Salvador, Tony, Genevieve Bell and Ken Anderson. 1999. "Design Ethnography." Design Management Journal 10, 4: 35-41.

Savery, Lawson, Geoffrey Soutar and John Weaver. 1993. "Stress and the Police Officer: Some West Australian Evidence." The Police Journal 66, 3: 277-290.

Seigne, Elizabeth. 1998. "Bullying at work in Ireland" Paper presented at Bullying at Work. 1998 Research Update Conference: Proceedings. Stafford: Staffordshire University.

Segurado Torres, Almudena, Esteban Agulló Tomas, Julio Rodríguez Suárez, Ma. Silveria Agulló Tomas, Joan Boada i Grau, J. and Raúl Medina Centeno. 2008. "Las Relaciones Interpersonales como Fuente de Riesgo de Acoso Laboral en la Policía Local." Psicothema 20, 4: 739-744.

Shallcross, Linda, Michael Sheehan and Sheryl Ramsay. 2008. "Workplace Mobbing: Experiences in the Public Sector." International Journal of Organisational Behaviour 13, 2: 5670.

Thacker, Rebecca. 1996. "A Descriptive Study of Situational and Individual Influences upon Individuals' Responses to Sexual Harassment." Human Relations 49, 8: 1105-1122. http://dx.doi.org/10.1177/001872679604900805

Ting-Toomey, Stella and John Oetzel. 2001. Managing Intercultural Conflict Effectively. Thousand Oaks, CA: Sage.

Tuckey, Michelle, Maureen Dollard, Patrick Hosking and Tony Winefield. 2009. "Workplace Bullying: The Role of Psychosocial Work Environment Factors." International Journal of Stress Management 16, 3: 215-232. http://dx.doi.org/10.1037/a0016841

Terpstra, David and Douglas Baker. 1991. "Sexual Harassment at Work: The Psychosocial Issues" in Marilyn Davidson and Jill Earnshaw (eds.) Vulnerable Workers: Psychosocial and Legal Issues. Chichester: Wiley, 179-201.

Tutino, John. 1986. From Insurrection to Revolution in Mexico. Princeton NJ: Princeton University Press.

Vartia, Maarit. 1993. "Psychological Harassment (bullying, mobbing) at Work." Pp. 149-152 in K. Kauppinnen-Toropainen (ed.) 
OECD Panel Group on Women, Worth and Health, Ministry of Social Affairs and Health, Helsinki.

Vartia, Maarit. 1996. "The Sources of Bullying: Psychological Work Environment and Organizational Climate." European Journal of Work and Organizational Psychology 5, 2: 203-214. http://dx.doi.org/10.1080/13594329608414855

Walsh, David. 2000. Doing Ethnography. Seale: Clive.

Zapf, Dieter and Heinz Leymann (eds.) 1996. "Foreword." European Journal of Work and Organizational Psychology 5, 2: 161164.

http://dx.doi.org/10.1080/13594329608414852
Zapf, Dieter, Carmen Knorz and Matthias Kulla. 1996. "On the Relationship between Bullying Factors, and Job Content, Social Work Environment, and Health Outcomes." European Journal of Work and Organizational Psychology 5, 2: 215237.

http://dx.doi.org/10.1080/13594329608414856

Zapf, Dieter and Claudia Gross. 2001. "Conflict Escalation and Coping with Workplace Bullying: A Replication and Extension." European Journal of Work and Organization Psychology 10, 4: 497-522.

http://dx.doi.org/10.1080/13594320143000834

Received on 12-03-2013

Accepted on 15-04-2013

Published on 23-04-2013

DOI: http://dx.doi.org/10.6000/1929-4409.2013.02.10

(C) 2013 Gustavo Fondevila; Licensee Lifescience Global.

This is an open access article licensed under the terms of the Creative Commons Attribution Non-Commercial License (http://creativecommons.org/licenses/by-nc/3.0/) which permits unrestricted, non-commercial use, distribution and reproduction in any medium, provided the work is properly cited. 